International Journal of Biology, Pharmaey and Allied Sciences (IJBPAS)

'A Bridge Betuen caboratory and QRender'

WwW.iibpas.com

\title{
PHARMACEUTICAL INDUSTRY EFFLUENT AS A VIABLE SUBSTRATE FOR POLYHYDROXYALKANOATE (PHA) PRODUCTION
}

\author{
SAXENA NK, TYAGI P AND SHARMA A* \\ Molecular Genetics Research Lab, Centre for Cellular and Molecular Biotechnology, Amity \\ Institute of Biotechnology, Amity University Uttar Pradesh, Sec-125, Noida, U.P. 201313 \\ *Corresponding Author: Aarti Sharma: E Mail: asharma11@amity.edu
}

Received $20^{\text {th }}$ July 2020; Revised $19^{\text {th }}$ Aug. 2020; Accepted $24^{\text {th }}$ Sept. 2020; Available online $1^{\text {st }}$ June 2021

\section{https://doi.org/10.31032/IJBPAS/2021/10.6.5532}

\begin{abstract}
Polyhydroxyalkanoates (PHAs) are microbial biopolymer that are accumulated in various microorganisms during nutrient deficient conditions. PHA possesses various characteristics like biodegradability, biocompatibility, high tensile strength and non-toxicity - which make it a suitable replacement for synthetic plastics. The high production cost of Polyhydroxyalkanoate is the key factor that hinders the commercialization of this biopolymer. In the current study, pharmaceutical industry effluent (PHI) has been used as a substrate and the conditions were standardized to maximize the yield of PHA and in process reducing the cost of PHA production. Maximum PHA yield was obtained at $\mathrm{pH}$ of 7.5 with peptone at a concentration of $30 \%$ PHI. Thus, this study demonstrates the utilization of pharmaceutical industrial effluent as a substrate for PHA production. This allows potential reduction in cost of the PHA production process while also bioremediating the industrial effluent; promoting sustainable development.
\end{abstract}

Keywords: Polyhydroxyalkanoates, Biodegradable, pharmaceutical industrial effluent, Media optimization

\section{INTRODUCTION}

Imagining the modern-day world without the dependency on petroleum based petroleum based synthetic plastics seems polymer has increased many folds [1]. inconceivable in the current day scenario, Since the production of synthetic organic 
polymer in $1950 \mathrm{~s}, 8.3$ billion tons $(9.1$ billion US tons) of plastic has been produced and almost every single piece of plastic that has been produced still exists in some form or the other [1]. The petroleumbased plastics are non-biodegradable and don't decompose, it ends up in the natural environment, seas or the landfills. The contemporary exploitation of the limited fossil resources for the fabrication of synthetic polymers incites pre-existing global problems such as global warming and green-house effect. Permanent elimination of these plastics is carried out usually by destructive thermal treatment, such as pyrolysis or combustion.

The incineration of the commonly utilized plastics elevates the concentration of $\mathrm{CO}_{2}$ inthe environment and contributes to the global warming as the chemical energy converts to thermal energy [2]. The abovementioned figures shine light upon the fact that the production and use of the petroleum-based polymers needs to reduce.

The near-permanent contamination of our natural environment because of overproduction and non-recycling of single use plastics is a huge concern, which will only keep on escalating if no alternative is introduced.There is a growing interest in the production of PHA from various renewable resources. Biotechnological method to manufacture biodegradable and bio-based polymeric material which can be used to replace commonly used nonbiodegradable plastics.

Polyhydroxyalkanoates (PHAs) arestorage material of carbon and energyproduced by numerous prokaryotic bacteria and archaea. The intracellular accumulation of PHA in form of inclusion bodies assists microbes under environmentally challenging and famine conditions such as high carbon and low nitrogen availability with their survivability [3-5]. Chemically, these are a class of biodegradable polyesters consisting of 3 - 6 hydroxyalkanoic acids. Up to 150 distinctive types of PHA structures have been distinguished so far [6], which is the reason PHA has been so extensively researched and makes it a strong contender instead of other bio-based polymer which has market capacity to replace conventional synthetic polymers [7] and useful for carbon reduction [8].

PHA attracts attention as it is easily produced from abundantly available renewable resources, its high thermoplasticity, bio-compostability, high tensile strength, insoluble in water, UV resistance, good barrier properties to gases, but foremost its biodegradability and biocompatibility [9]. The incorporation of production process of PHA into bioremediation, biorefining and treatment facilities of waste is being meticulously inspected so as to make these processes economically efficient and sustainable [10]. 
In last decade, the cost of PHAcommodities has been reduced due the growing financial investments made in the production, fabrication and marketing of biodegradable polymers. Nevertheless, the absolute market commercialization of PHA is still crippled by the utilization of pure culture fermentation and steep cost of media [11]. Efforts have been made in recent years to successfully work on cost reduction by utilization of industrial wastes, wastewater and mixed cultures as substrate [12]. Hence, mass application of PHA can be achieved due to lower principal investment and lessened operational costs of production plants [13].

The rapid surge in world-wide demand for production of medicinal drugs has resulted in emergence of pharmaceutical industry as one of the chief polluters of effluents and solid waste [14]. Pharmaceutical effluents are highly hazardous and the pollutants contains various chemicals, metabolites, personal care products, prescription drugs, non-biodegradable organic matter such as animal and plant steroids, antibiotics, reproductive hormones and other broadly used chemicals such as reaction residues, spent solvents, heavy metals etc. [15-17]. The effluent, especially in the developing countries in not managed properly and is eventually discharged in large amounts in surrounding ecosystem. Most of the toxicants present in the discharge gets accumulated in soil, water bodies and other biological systems, exceeding the critical threshold levels. Since these pollutants often are disastrous to the human wellbeing, therefore in recent years, various studies have been undertaken to study the effect of pharmaceutical industrial effluent on the ecosystem and human health.

The current study was aimed at using the pharmaceutical industrial effluent as a viable substrate for production of PHA to reduce the cost of production and employing the pollutant as raw material. Optimization of physical conditions and medium components was done to maximize the yield of PHA. Fermentation at lab scale was also carried out to test these standardized conditions for maximum PHA production.

\section{MATERIALS AND METHOD}

\subsection{Collection of samples and isolation of bacterial strains}

Pharmaceutical industrial effluent (PHI) was obtained from a facility in Narkanda, Himachal Pradesh $\left(31.2578^{\circ} \mathrm{N}, 77.4602^{\circ}\right.$ E) in a sterile plastic bottle. It was refrigerated until further processing. Soil sample from the facility, a few inches below the surface, was also obtained for the purpose of isolation of bacterial strain. The $\mathrm{pH}$ of the effluent was checked along with the TDS using a handheld TDS meter. With the aim of isolation of a putative PHA producing bacterial strain, nutrient agar 
media $(0.3 \%$ beef extract, $0.5 \%$ peptone, $2 \%$ agar and $0.5 \%$ sodium chloride) was prepared and autoclaved at $121^{\circ} \mathrm{C}$ at $15 \mathrm{psi}$ for 20 minutes.

Once the media cools down to $50^{\circ} \mathrm{C}-$ $55^{\circ} \mathrm{C}$, the prepared media was dispensed into sterilized petri plates and left to solidify. Isolation of bacterial strains from soil sample was done by mixing $1 \mathrm{~g}$ of sample in $10 \mathrm{ml}$ double distilled water. It was subjected to ten-fold serial dilution. Bacterial strains were isolated by spread plating $10^{-6}, 10^{-7}$ and $10^{-8}$ dilutions on nutrient agar plates [18]. The plates of agar were then incubated for $24-48 \mathrm{~h}$ at $37^{\circ} \mathrm{C}$. After the completion of the incubation, each morphologically distinguishable colony was selected by an inoculation loop post sterilization and was further streaked on fresh plates of nutrient agar for isolation of pure culture of the desired bacterial strain. Each isolated colony was further used in screening for their PHA production potential.

\subsection{Screening of PHA producing bacterial}

Screening of bacterial strains was done on the basis of their potential for PHA production by via Nile blue A (a heat labile lipophilic oxazine dye) which is quite specific towards PHA than other stains.

Stock of Nile blue A was formulated using DMSO $(1 \mathrm{mg} / \mathrm{ml})$ and $125 \mu \mathrm{l}$ dye was filtered by syringe filters and added to a medium before plating to make the final concentration $0.5 \mu \mathrm{g} / \mathrm{ml}$. The media contained $\mathrm{CaCl}_{2}(.2 \mathrm{~g} / \mathrm{L}), \mathrm{KH}_{2} \mathrm{PO}_{4}(1 \mathrm{~g} / \mathrm{L})$, $\mathrm{MgSO}_{4} .7 \mathrm{H}_{2} \mathrm{O} \quad(.2 \mathrm{~g} / \mathrm{L}), \quad$ Peptone (1g/L)Glucose (10g/L) and Agar (20g/L) with $\mathrm{pH}$ was adjusted to $7.0 \pm 0.5$. Post solidification, each previously isolated bacterial strains were spotted onto the fresh plates of agar and the growth of these bacteria occurred in the presence of this Nile Blue A dye. These agar plates were incubated for 72 hat $37^{\circ} \mathrm{C}$. This dye helped us to assess putative PHA producers at a given time frame during the growth phase and a strong distinction between PHAnegative and PHA-positive producing strains can be observed under the UV illumination. Upon irradiation with UV light, the isolates emitting fluorescence were selected as putative PHA bioaccumulators. Despite Nile blue A being highly specific for intracellular PHA granules factors like granularity and pigmentation often contribute to the fluorescence emission even in the absence of PHA. Hence the qualitative screening alone cannot be employed for identification of strains assimilating PHA [19]. Hence, quantitative screening was done so as to help us identify PHA assimilating strains

\subsection{Screening for PHA production by} PHA induction media (PIM)

Strains that were possibly accumulating PHA were further inoculated in $250 \mathrm{ml}$ of 
PHA induction media (PIM) containing glucose $(10 \mathrm{~g} / \mathrm{L}), \mathrm{KH}_{2} \mathrm{PO}_{4}(1 \mathrm{~g} / \mathrm{L}), \mathrm{CaCl}_{2}$ $(.2 \mathrm{~g} / \mathrm{L})$ and Peptone $(1 \mathrm{~g} / \mathrm{L})$ and the $\mathrm{pH}$ was adjusted to $7.0 \pm 0.5$. Each screened strain was inoculated in $5 \mathrm{ml}$ nutrient broth for the preparation of the inoculum and were incubated at $37^{\circ} \mathrm{C}$ overnight and was added to PIM at a concentration of $2 \%$. Incubation of these flasks was done for 72 hat $37^{\circ} \mathrm{C}$. The bacterial cells were obtained by centrifugation for 10 minutes at $6000 \mathrm{rpm}$. The cells were then treated with sodium hypochlorite and boiling chloroform [20]. In order to obtain PHA, the chloroform was allowed to dry out. The bacterial strain that yielded the maximum PHA was selected or further studies.

\subsection{Utilization of PHI as substrate and spectrophotometry analysis}

PHI based PIM was prepared by replacing the carbon source in PIM by the industrial effluent. The $\mathrm{pH}$ was set to $7.0 \pm 0.5$ before autoclaving. The bacterial strain inoculum was prepared in nutrient broth 24 hours prior to inoculation and $2 \%$ inoculum was introduced to $250 \mathrm{ml}$ PHI based PIM media after autoclaving. The culture was kept for 72 hours at $37^{\circ} \mathrm{C}$. After the incubation period was over the cells were pelleted and extraction of PHA was carried out. A spectrophotometric method for analysis characterization of PHA was developed by Law and Slepecky. It showed the conversion of Polyhydroxybutyrate into crotonic acid when the polymer is boiled in sulphuric acid. Spectrophotometric analysis of this crotonic acid was done and the maxima was detected at $235 \mathrm{~nm}$. Similarly, the polymer was dispelled in $10 \mathrm{ml}$ sulphuric acid in a test tube. Commercially available hydroxyalkanoic acid (Sigma), was also dispelled in $10 \mathrm{ml}$ sulphuric acid. All the tubes were boiled for 10 mins at $100^{\circ} \mathrm{C}$, followed by cooling of these tubes. In a quartz cuvette, $1 \mathrm{ml}$ of the cooled solution was transferred and the absorbance was measured. Sulphuric acid which was previously boiled was used as blank [21]. The peaks obtained at a particular wavelength were compared for the standard and the sample.

\subsection{Effect of physical conditions on PHA production}

The effect of varied temperature on growth of bacteria and subsequent PHA accumulation during incubation was investigated. The incubation temperature of the culture was ranged between $30^{\circ} \mathrm{C}-$ $40^{\circ} \mathrm{C}$. After $72 \mathrm{~h}$ of incubation, the bacterial cells were obtained by centrifugation for $10 \mathrm{~min}$ at $6000 \mathrm{rpm}$. The cells were subjected to sodium hypochlorite and boiling chloroform. After PHA was obtained and weighed, the temperature at which maximum PHA accumulation occurred, was selected. Growth of culture in stationary conditions versus the effect of agitated conditions on the growth of 
bacteria was also studied. Isolate was inoculated in flasks containing PHI based PIM and incubated at $37^{\circ} \mathrm{C}$. The flasks were separately kept in stationary and agitated condition ranging from 50 to 200 rpm for $72 \mathrm{~h}$. The bacterial cells were acquired by centrifugation at $6000 \mathrm{rpm}$ and then were treated by sodium hypochlorite and boiling chloroform. The obtained PHA was weighed and the best state was selected for maximum PHA yield.

The effect of $\mathrm{pH}$ on yield of PHA was examined by varying the $\mathrm{pH}$ between $4.0-$ 10.0. The $\mathrm{pH}$ was regulated prior to sterilization of PHI based PIM medium with 1M Sodium Hydroxide or 1M Hydrochloric acid [22]. The bacterial isolate was inoculated in different flasks with varying $\mathrm{pH}$ and were incubated at $37^{\circ} \mathrm{C}$ for $72 \mathrm{~h}$. After the completion of the incubation period, the PHA was extracted using sodium hypochlorite and boiling chloroform. Chloroform was evaporated to obtain PHA. The PHA obtained from varied $\mathrm{pH}$ source was weighed and the best $\mathrm{pH}$ was used to proceed further.

The effect of incubation time on the yield of PHA was determined by varying the time of incubation of the PHI based PIM media between 12 - 96 h. Nutrient broth was used for the preparation of inoculum of the PHA producing bacterial strain and $2 \%$ $\mathrm{v} / \mathrm{v}$ of this strain was inoculated in PHI based PIM. PHA was extracted at different time frames ranging from 12 hours to 96 hours. The result of these extraction was compared and analysed to assess the best incubation time for maximum PHA yield.

\subsection{Effect of cultural condition on PHA production}

Nitrogen being a key factor in microbial growth and PHA accumulation, different inorganic and organic sources of nitrogen was tested to determine their effects on yield of PHA. The organic sources of nitrogen were peptone, beef extract, yeast extract, tryptone and urea. Also, the inorganic sources of nitrogen used were ammonium chloride and ammonium sulphate. The bacterial isolate was inoculated in different flasks containing varied nitrogen sources. These flasks were then incubated for 72 hours at $37^{\circ} \mathrm{C}$ and post incubation completion period PHA was extracted using sodium hypochlorite and boiling chloroform method. The obtained PHA was weighed and the best nitrogen source was utilized for optimization. Pharmaceutical industrial effluent (PHI) was used as a carbon source for the production of PHA. The glucose in PIM was replaced by PHI. The concentration of PHI determines the accumulation of PHA. Hence, concentration was varied between 10\% 100\%. PHI based PIM with varied PHI concentration was prepared and sterilized by autoclaving at $121^{\circ} \mathrm{C}$ for 20 mins at 
15psi. Post sterilization inoculation of media was done with the bacterial isolate for $72 \mathrm{~h}$ at $37^{\circ} \mathrm{C}$. After the completion of incubation period the bacterial cells were obtained by centrifugation for 10 mins at $6000 \mathrm{rpm}$. The cells obtained were subjected to sodium hypochlorite and boiling chloroform treatment to acquire PHA. The obtained PHA was then weighed and the concentration of PHI which yielded maximum PHA was selected for further processing.

\subsection{PHA quantification and lab-scale fermentation}

Standardized and optimized parameters for maximum PHA yield were employed to formulate $100 \mathrm{ml}$ PHI based PIM. The media was autoclaved for $20 \mathrm{mins}$ at $121^{\circ} \mathrm{C}$ at $15 \mathrm{psi}$ before utilization. The selected isolate, which aggregate maximum PHA, was inoculated in nutrient broth 24 hours prior to inoculation and $2 \%(\mathrm{v} / \mathrm{v})$ of this inoculum was inoculated under sterile conditions in 3 different PHI based PIM. The culture was incubated at $37^{\circ} \mathrm{C}$ for $72 \mathrm{~h}$. After the completion of the incubation period the cells were obtained by centrifugation at $6000 \mathrm{rpm}$. Aluminium foil was used to make small cups which were then weighed. Distilled water was use to wash cell pellet and was then vortexed with $1-2 \mathrm{ml}$ double distilled water to homogenize. This mixture was poured in three different pre-weighed aluminium.
These aluminium cups were kept in hot air oven to desiccate. The cups were weighed on a daily basis until a constant weight was achieved.

The equation used to calculate the $\%$ of PHA accumulation is as follows.

Cell dry mass $=$ Weight of cup (with dried pellet) - Initial weight of cup

\% PHA = Dry weight of extracted PHA (g/L)/Cell dry mass (g/L) X100 (\%)

The optimized cultural and physical conditions were mirrored in a $5 \mathrm{~L}$ lab scale fermenter with a working volume of $2.5 \mathrm{~L}$. Prior fermentation, the fermenter was washed, wiped clean with ethanol and filled with double distilled water before autoclaving at $121^{\circ} \mathrm{C}$ for 20 mins at 15 psi. The fermenter was then allowed to cool and decanted before optimized PHI based PIM was added to the fermenter followed by autoclaving. The bacterial inoculum of the strain was prepared in nutrient broth, 24 hours prior to the inoculation and $2 \%(\mathrm{v} / \mathrm{v})$ of the inoculum was inoculated under sterile conditions through the inoculation port. The fermentation conditions were kept at $150 \mathrm{rpm}$ at $37^{\circ} \mathrm{C}$ for 72 hours with constant aeration. After the completion of the incubation period, the bacterial cells were harvested by centrifugation and extraction of PHA was done by sodium hypochlorite-boiling chloroform method. 


\section{RESULTS}

Pharmaceutical industrial effluent (PHI) was a transparent brown coloured liquid with a $\mathrm{pH}$ of 3.45 and TDS was observed to be $1050 \mathrm{ppm}$. The garden soil was serially diluted using $1 \mathrm{~g}$ of soil sample. After 10fold serial dilution, diluents $10^{-6}, 10^{-7}$ and $10^{-8}$ were spread on a nutrient agar plate. The agar plates were incubated at $37^{\circ} \mathrm{C}$ for $24-48$ h. About 21 morphologically and visually distinct colonies were obtained and were screened by using Nile Blue A. Upon irradiation with UV light out of 21 isolates, 6 isolates emitted fluorescence which were selected as putative PHA bio-accumulators. PIM was used to for small scale extraction so as to check for PHA assimilation in the 6 putative PHA producing strains. Strain named ART_27N yielded maximum PHA out of all 6 putative PHA producing strains. The extracted PHA was subjected to spectrometric analysis by Law and Slepecky method. The extracted polymer showed peak absorbance at $235 \mathrm{~nm}$ as similar to commercially available hydroxyalkanoic acid which shows that the extracted polymer was also hydroxyalkanoic acid (Figure 1).

Effect of varied temperature was observed and maximum yield of PHA was observed at $37^{\circ} \mathrm{C}$ which was $84 \mathrm{mg} / \mathrm{L}$ (Figure 2). The growth of bacterial culture and its subsequent effect on PHA yield at, stationary and non-stationary conditions was observed. The best yield of $108 \mathrm{mg} / \mathrm{L}$ was observed at $150 \mathrm{rpm}$ (Figure 3). The effect of age of the inoculum on PHA production potential was observed. The inoculum with the incubation period of 18 $\mathrm{h}$ yielded $104 \mathrm{mg} / \mathrm{L}$ PHA which was found to be maximum amongst all the other incubates, although there was not a very significant difference amongst the yield of various other incubates (Figure 4). The effect of incubation period post inoculation of the on the yield of PHA was observed. The maximum yield of $108 \mathrm{mg} / \mathrm{L} \mathrm{mg}$ was observed after 72 hours of incubation while extraction done at 12, 24 and 36 hours yielded no PHA at all (Figure 5). Effect of $\mathrm{pH}$ variation on bacterial growth and consequent PHA production was examined to maximize the production of PHA. It was observed that maximum PHA extracted was $116 \mathrm{mg} / \mathrm{L}$, when the bacteria were allowed to grow in medium with $\mathrm{pH}$ as 7.5 (Figure 6).

Nitrogen is an important factor determining the accumulation of PHA hence [23], different nitrogen sources were employed in order to maximize the production of PHA. Upon extraction the PHA was weighed and it was observed that the inorganic sources of nitrogen did not yield any PHA along with urea and amongst organic sources of nitrogen, peptone produced maximum PHA which was 112 
mg/L (Figure 7). The carbon source in PIM was

replaced by PHI so as to utilized the industrial effluent for production of PHA. The attained PHA was weighed and the maximum yield of $124 \mathrm{mg} / \mathrm{L}$, was found to be at a concentration of $30 \%$ of $\mathrm{PHI}$ in the medium (Fig 8).Post optimization of physical and cultural conditions for maximum PHA production, PHA quantification was done using $100 \mathrm{ml} \mathrm{PHI}$ based PIM medium. The optimized physical and cultural conditions were replicated in a $5 \mathrm{~L}$ with a working capacity of $2.5 \mathrm{~L}$. The results indicated an extraction of $35.2 \%$ of $.245 \mathrm{~g} / \mathrm{L}$ cell dry weight (Table 1).

\section{Spectrophotmetric analysis}

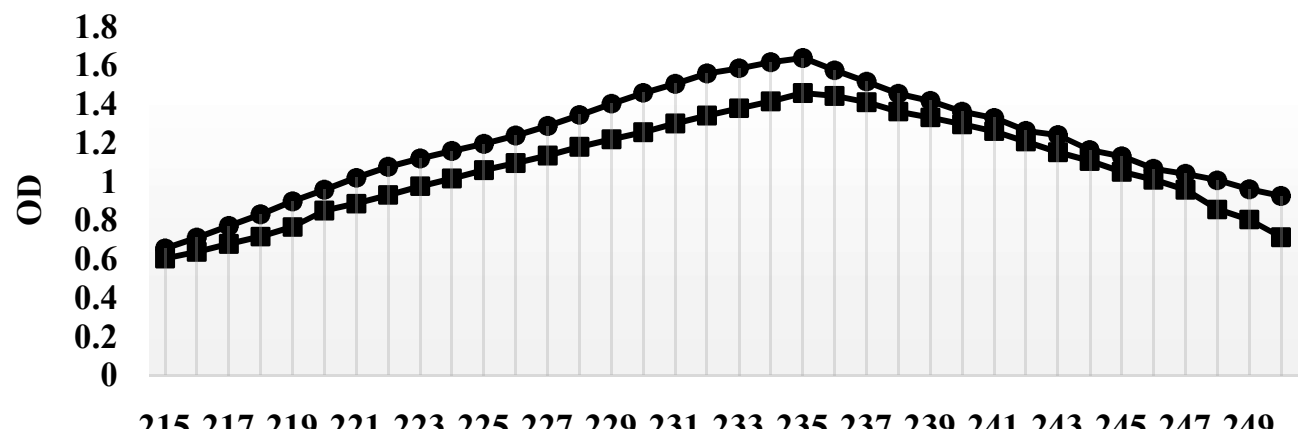

215217219221223225227229231233235237239241243245247249

Wavelength (nm)

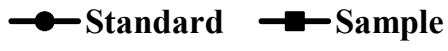

Figure 1: Spectrophotometric analysis of extracted PHA from Pharmaceutical industrial waste

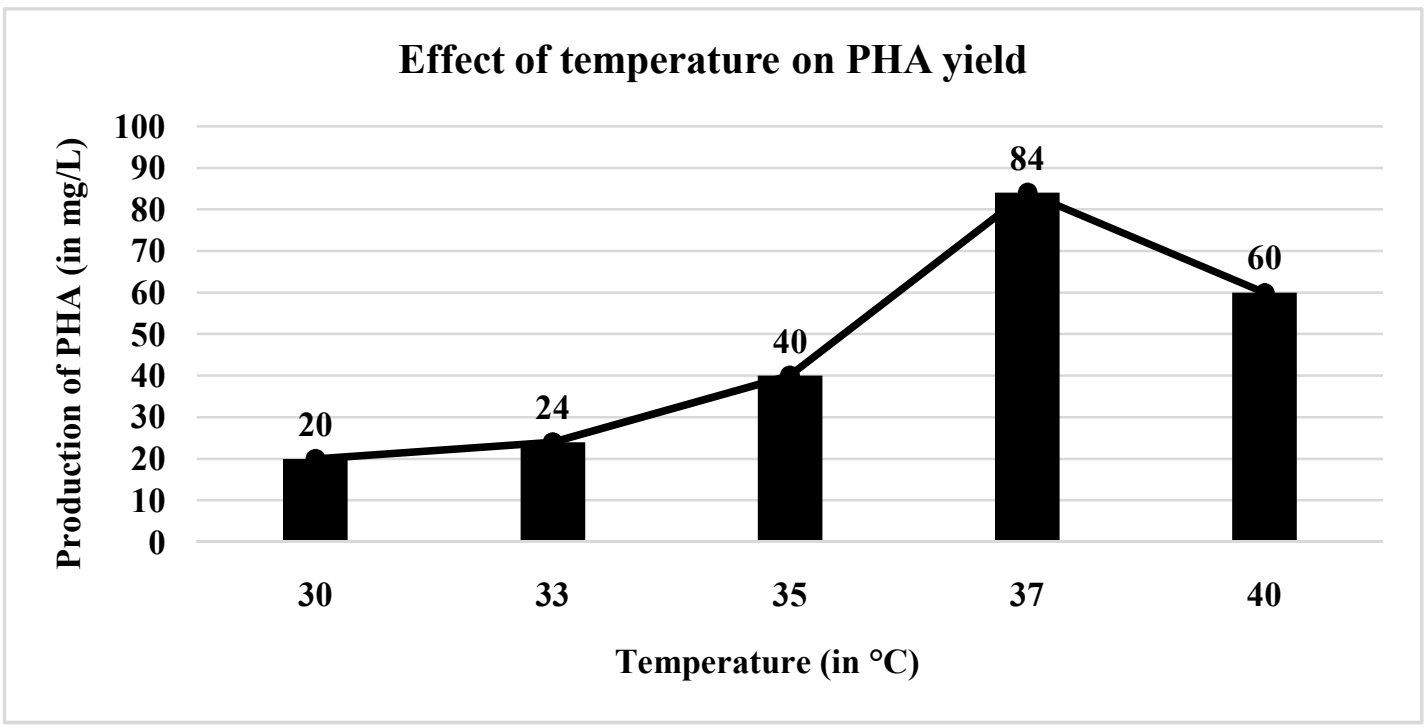

Figure 1: Effect of temperature on yield of PHA 


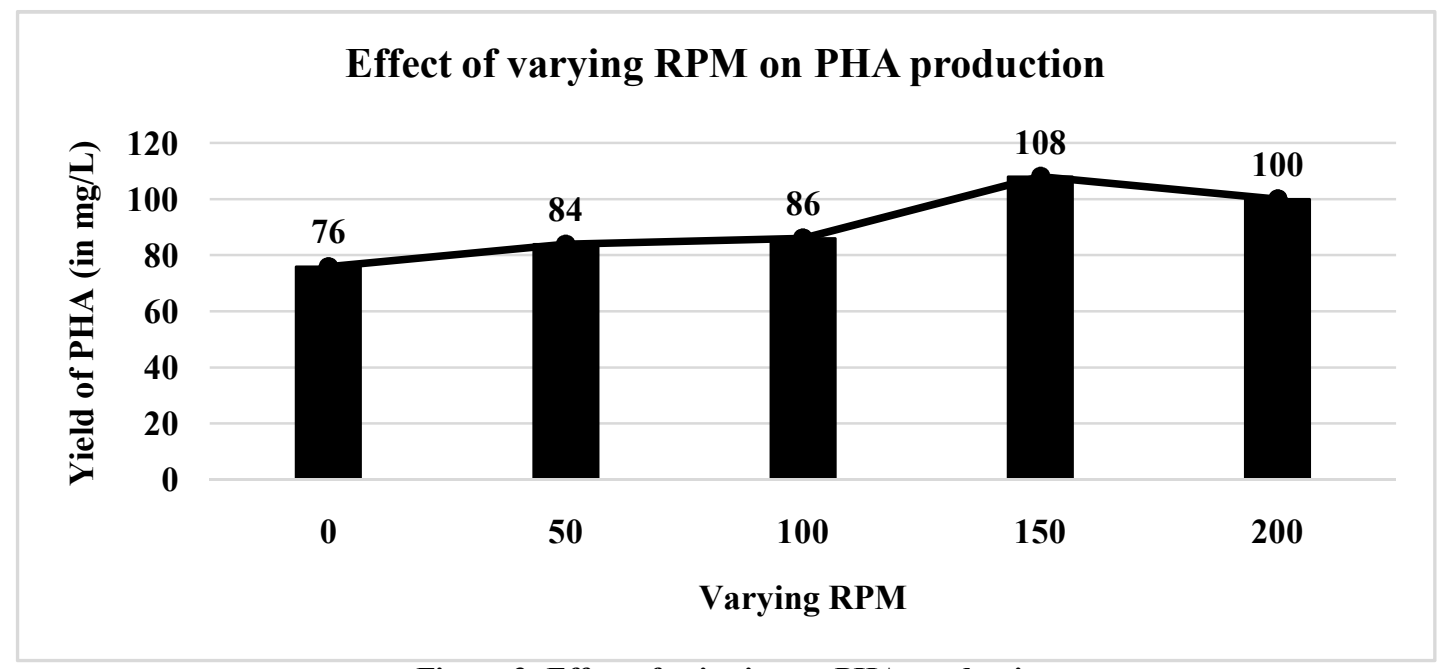

Figure 3: Effect of agitation on PHA production

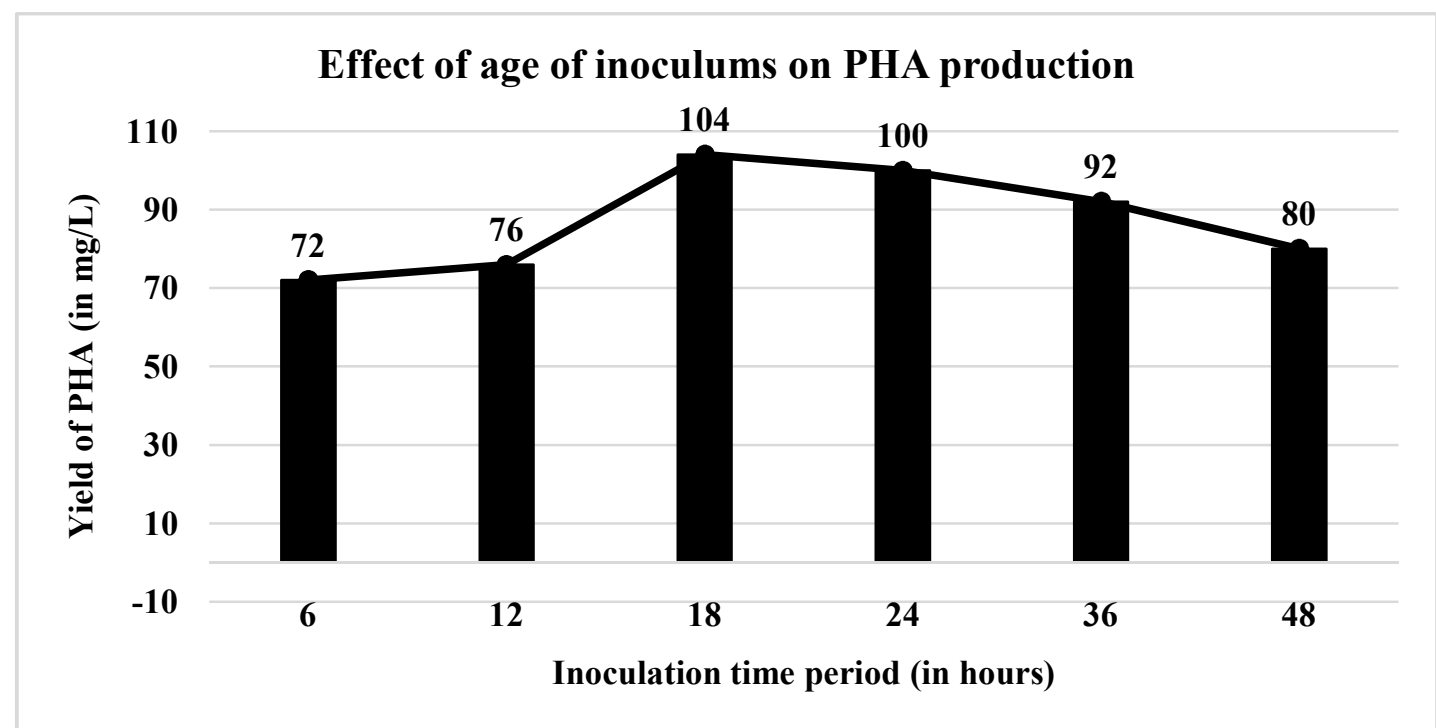

Figure 4: Effect of age of inoculums on PHA production

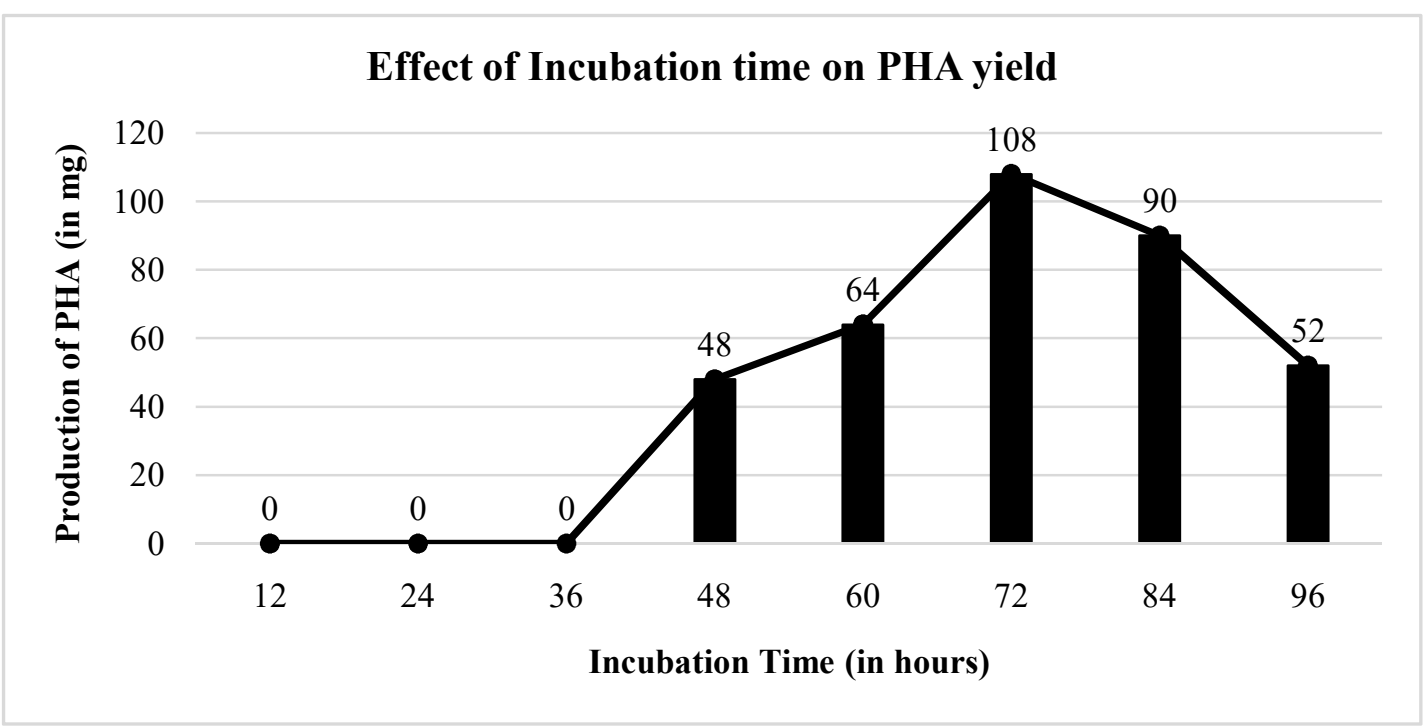

Figure 5: Effect of Incubation time of bacterial culture on PHA production 


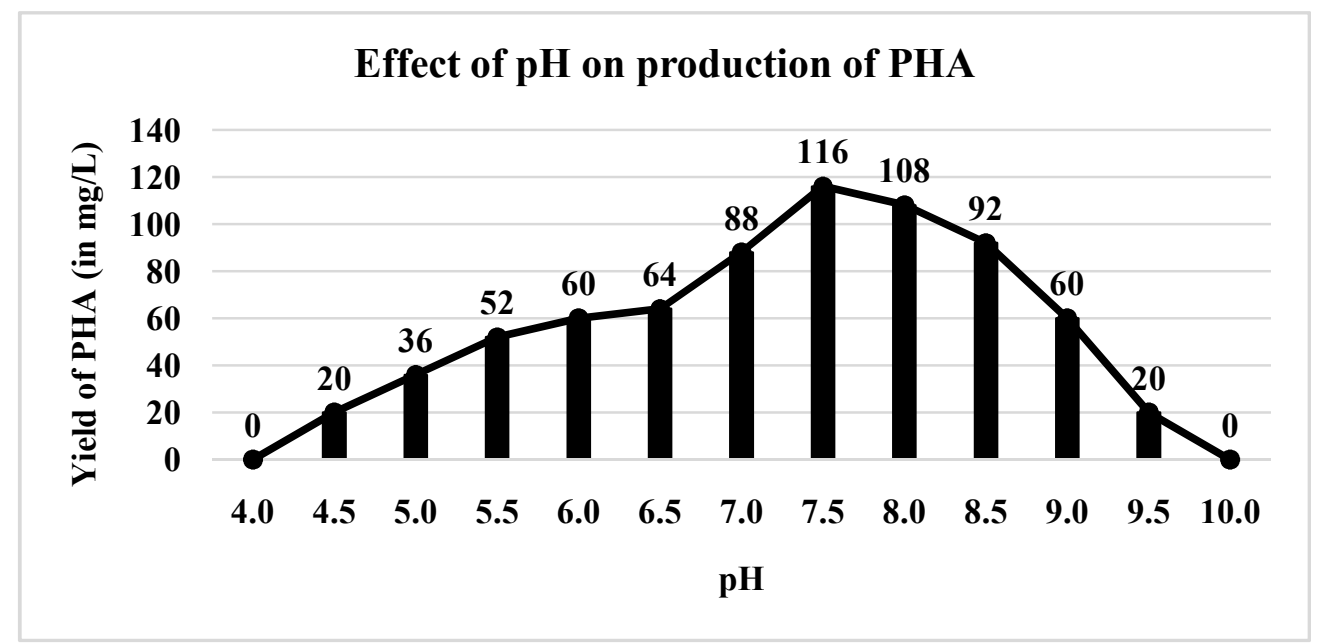

Figure 6: Effect of pH on production of PHA

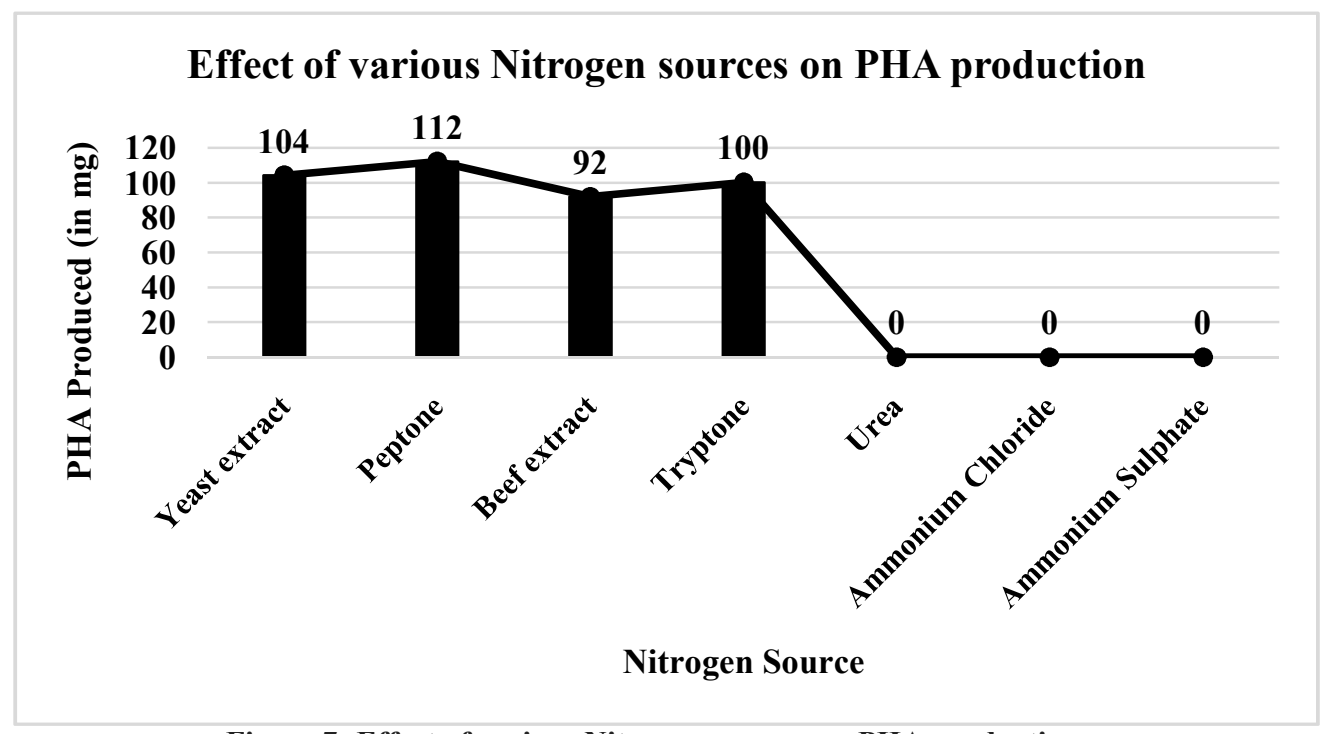

Figure 7: Effect of various Nitrogen sources on PHA production

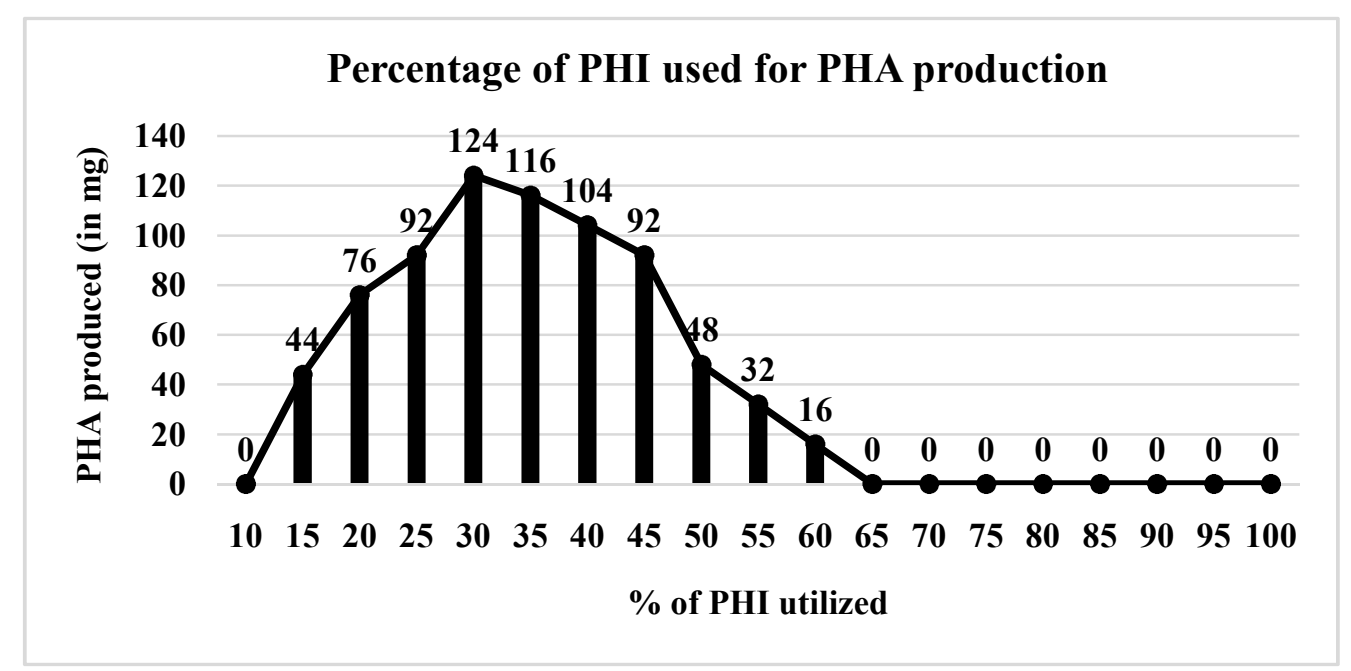

Figure 8: PHI concentration used for maximum PHA production

Table 1

\begin{tabular}{|c|c|c|}
\hline Cell dry weight $(\mathrm{g} / \mathrm{L})$ & PHA produced $(\mathrm{g} / \mathrm{L})$ & PHA yield (\%) \\
\hline 0.245 & 0.0862 & 35.2 \\
\hline
\end{tabular}




\section{CONCLUSION}

Bacterial strain isolation was done from pharmaceutical industry soil sample for screening PHA producing strains. Industrial effluent collected was transparent, brown coloured liquid with a $\mathrm{pH}$ of 3.45 and TDS of $1050 \mathrm{ppm}$. Screening of isolated bacteria allowed identification of strain ART_27N which produced maximum PHA. This bacterial isolate was able to utilize PHI as a carbon source. Spectrophotometric analysis confirmed the extracted polymer as PHB. Physical and cultural conditions were optimized which showed that ART_27N produced maximum PHA at $37^{\circ} \mathrm{C}$ under agitation at $150 \mathrm{rpm}$ with inoculum age of $18 \mathrm{~h}$. Peptone was found to be the best nitrogen source which yielded maximum PHA at a $\mathrm{pH}$ of 7.5 after an incubation period of 72 h. Lab-scale batch fermentation was carried out which yielded $35.2 \%$ PHA of cell dry weight. Thus, we successfully demonstrate the utilization of PHI as a substrate and the optimization of PHA production using the waste.

\section{Acknowledgement}

The authors would like to acknowledge Amity University Uttar Pradesh for the infrastructural support provided. The authors have no conflict of interest to declare.

\section{REFERENCES}

[1] Geyer R, Jambeck JR, Law KL. Production, use, and fate of all plastics ever made. Sci Adv. 2017; 3(7): 25-9.

[2] Braunegg G, Bona R, Koller M. Sustainable Polymer Production. Polym Plast Technol Eng. 2004 Nov; 43(6): 1779-93.

[3] Obruca S, Sedlacek P, Koller M, Kucera D, Pernicova I. Involvement of polyhydroxyalkanoates in stress resistance of microbial cells: Biotechnological consequences and applications. Vol. 36, Biotechnology Advances. Elsevier Inc.; 2018. p. 856-70.

[4] Kourmentza C, Plácido J, Venetsaneas N, Burniol-Figols A, Varrone C, Gavala HN, et al. Recent advances and challenges towards sustainable polyhydroxyalkanoate (PHA) production. Vol. 4, Bioengineering. MDPI AG; 2017.

[5] Slaninova E, Sedlacek P, Mravec F, Mullerova L, Samek O, Koller M, et al. Light scattering on PHA granules protects bacterial cells against the harmful effects of UV radiation. Appl Microbiol Biotechnol. 2018 Feb; 102(4): 1923-31.

[6] Chen GQ. A microbial polyhydroxyalkanoates based bio- and materials industry. Vol. 38, Chemical Society Reviews. 2009. p. 2434-46. 
[7] Shrivastav A, Kim HY, Kim YR. Advances in the applications of polyhydroxyalkanoate nanoparticles for novel drug delivery system. Vol. 2013, BioMed Research International. 2013.

[8] Verlinden RAJ, Hill DJ, Kenward MA, Williams CD, Radecka I. Bacterial synthesis of biodegradable polyhydroxyalkanoates. Vol. 102, Journal of Applied Microbiology. 2007. p. 1437-49.

[9] Zinn M, Witholt B, Egli T. Occurrence, synthesis and medical application of bacterial polyhydroxyalkanoate. Vol. 53, Advanced Drug Delivery Reviews. 2001. p. 5-21.

[10] Pittmann T, Steinmetz H. Polyhydroxyalkanoate Production on Waste Water Treatment Plants: Process Scheme, Operating Conditions and Potential Analysis for German and European Municipal Waste Water Treatment Plants. Bioengineering. 2017 Jun; 4(4): 54.

[11] Chanprateep S. Current trends in biodegradable

polyhydroxyalkanoates. Vol. 110, Journal of Bioscience and Bioengineering. 2010. p. 621-32.

[12] Wang YJ, Hua FL, Tsang YF, Chan SY, Sin SN, Chua H, et al.
Synthesis of PHAs from waster under various $\mathrm{C}: \mathrm{N}$ ratios. Bioresour Technol. 2007 May; 98(8): 1690-3.

[13] Bengtsson S, Werker A, Christensson $\mathrm{M}$, Welander $\mathrm{T}$. Production of polyhydroxyalkanoates by activated sludge treating a paper mill wastewater. Bioresour Technol. 2008 Feb; 99(3): 509-16.

[14] Anyakora C, Nwaeze K, Awodele O, Nwadike C, Arbabi M, Coker $\mathrm{H}$. Concentrations of heavy metals in some pharmaceutical effluents in Lagos, Nigeria. Environ Chem. 2011; 3(February): 25-31.

[15] Vuppala NVS, Suneetha C, Saritha V. Study on treatment process of effluent in Bulk drug industry. Int J Res Pharm Biomed Sci. 2005; 3(3): 1095-102.

[16] Ramola B. Heavy Metal Concentrations in Pharmaceutical Effluents of Industrial Area of Dehradun (Uttarakhand), India. J Environ Anal Toxicol. 2013 May; 03(03): 1-4.

[17] Chelliapan S, Yuzir A, Din MFM, Sallis PJ. Anaerobic Pre-treatment of Pharmaceutical Wastewater using Packed Bed Reactor. Int J Chem Eng Appl. 2011; 2(1): 32-7. [18] García-Armesto MR, Prieto M, 
Alonso C, García-López ML, García-Fernández MC, Otero A. Numerical Taxonomy of Psychrotrophic Bacteria Isolated from Raw ewes' Milk. J Dairy Res. 1993; 60(3): 371-83.

[19] Ratnaningrum D, Saraswaty V, Priatni S, Lisdiyanti P, Purnomo A, Pudjiraharti S. Screening of polyhydroxyalkanoates (PHA)producing bacteria from soil bacteria strains. IOP Conf Ser Earth Environ Sci. 2019; 277(1).

[20] Gamal RF, Abdelhady HM, Khodair TA, El-Tayeb TS, Hassan EA, Aboutaleb KA. Semi-scale production of PHAs from waste frying oil by Pseudomonas fluorescens S48. Brazilian J Microbiol. 2013; 44(2): 539-49.

[21] Law JH, Slepecky RA. Assay of poly-beta-hydroxybutyric acid. J Bacteriol. 1961 Jul; 82: 33-6.

[22] Yogesh S, Nirmal Kumar G, Saravanakumar P, Dhayananth N RBNG. Effect oF $\mathrm{pH}$ and Temperature on Synthesis of Polyhydroxyalkanoates from Dairy Waste Water. Int J Eng Res Technol. 2014; 3(1): 1081-6.

[23] Singh Saharan B, Grewal A, Kumar P. Biotechnological Production of Polyhydroxyalkanoates: A Review on Trends and Latest Developments. Chinese J Biol. 2014 Feb 24; 2014: 1-18. of 